\title{
Laboratory assessment of physical and chemical methods of preserving urine specimens
}

\author{
P. G. WATSON AND B. I. DUERDEN 1 \\ From the Department of Bacteriology, Edinburgh University Medical School, Teviot Place, \\ Edinburgh EH8 $9 A G$
}

SUMMARY Three methods of preserving simulated specimens of urine were studied with six test o strains of bacteria. Viable counts were measured by a surface viable count and by the filter-paperstrip method during a holding period of 72 hours. Refrigeration at approximately $4^{\circ} \mathrm{C}$ was effective

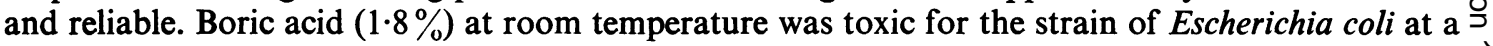
density of $10^{7} \mathrm{cfu} / \mathrm{ml}$ but this may not be significant at the higher concentration of bacterial cells $\overrightarrow{\vec{C}}$ often found in clinical specimens. $\mathrm{NaCl}$-polyvinylpyrrolidone (PVP) solutions containing PVP of mol. wt 44000 or 700000 were not effective; they were toxic for the Gram-negative strains and did not retard the growth of Micrococcus subgroup 3. The two methods of measuring viable counts were compared for specimens held under different conditions; the specificity of the filter-paper-strip method was high but the sensitivity was low when many of the specimens contained approximately $10^{5} \mathrm{cfu} / \mathrm{ml}$.

The laboratory diagnosis of a primary urinary tract infection depends upon the demonstration of significant bacteriuria, ie, $>10^{5}$ organisms $/ \mathrm{ml}$, by quantitative culture of two consecutive freshly voided specimens of urine (Kass, 1956; 1957). Most human urine readily supports bacterial growth (Asscher et al., 1968) and specimens of urine are frequently contaminated by organisms from the lower urethra or the external genitalia. If there is a delay between the collection of a specimen and quantitative culture, the contaminants can multiply to give a false 'significant' result.

Kass (1956) recommended that specimens of urine should be examined within one hour of collection, but it is often impossible to deliver specimens to the laboratory within an hour. Accordingly, methods of preservation of the specimen have been devised. Refrigeration at approximately $4^{\circ} \mathrm{C}$ is effective for up to 48 hours (Kass, 1956), and Porter and Brodie (1969) found that $1.8 \%$ boric acid in urine preserved viable counts in clinical specimens for three days at room temperature. Amies and

${ }^{1}$ Present address: Department of Medical Microbiology, University of Sheffield Medical School, Beech Hill Road, Sheffield S10 2RX

Received for publication 11 November 1976
Corpas (1971) found that the addition of $3 \mathrm{ml}$ of an aqueous solution of $30 \% \mathrm{NaCl}-3 \%$ polyvinyl- $\overline{\vec{a}}$ pyrrolidone (PVP) to $7 \mathrm{ml}$ of urine preserved viable counts in simulated laboratory specimens and in clinical specimens for four to six days.

The present study was undertaken to compare these methods of preservation with simulated specimens of pooled urine seeded with known 3 concentrations of test organisms.

\section{Material and methods}

\section{ORGANISMS}

One strain each of Escherichia coli, Pseudomonas aeruginosa, Klebsiella aerogenes, Proteus mirabilis, 0 Micrococcus subgroup 3, and Streptococcus faecalis N was used. They were isolated from infected urine N specimens and identified by the methods of Cowan and Steel (1965).

URINE

Midstream urine was collected from healthy male volunteers who had not taken any antimicrobialo agent during the previous three days. Urine collected $\mathbb{\odot}$ on a single day was pooled and sterilised by Seitzक्षे filtration. The $\mathrm{pH}$ was measured before and after $\frac{\varrho}{\sigma}$ filtration; no change greater than $0.1 \mathrm{pH}$ unit occurred. 
METHODS OF DETERMINING TOTAL VIABLE COUNTS

\section{Surface viable count}

The following modification of the method of Miles et al. (1938) was used. A Finnpipette (Buckley Membranes Ltd, Amersham, England) with sterilised disposable tips was used to deliver $0 \cdot 1 \mathrm{ml}$ into $0.9 \mathrm{ml}$ of diluent to make serial 10 -fold dilutions (Duerden and Moyes, 1976). Five 0.02 ml drops of each dilution were delivered on to Columbia agar (Oxoid) using 50-dropper pipettes (Cruickshank, 1968). After overnight incubation at $37^{\circ} \mathrm{C}$ the colonies from the dilution that gave the largest number of colonies without confluence were counted using a colony counter (Sintacel).

\section{Filter-paper-strip method}

Two filter-paper strips (Postlip, fibre-free) with a 'foot' measuring $13 \times 6 \mathrm{~mm}\left(\frac{1}{2} \times \frac{1}{4}\right.$ in) were dipped into each simulated specimen, held upright to absorb excess fluid, and then impressed on MacConkey agar (Oxoid). After overnight incubation the colonies in the area of the 'foot' were counted. The method was calibrated for each test strain.

\section{COMPARISON OF METHODS OF PRESERVING} SIMULATED SPECIMENS OF URINE

An overnight culture of each test strain in pooled urine was serially diluted in urine to give six simulated specimens with dilution factors of $10,10^{3}, 10^{4}$, $10^{5}, 10^{6}$, and $10^{7}$. Immediately (time zero) the viable count of each specimen was determined by both methods. Five parallel series of six specimens were held as follows:

(1) at room temperature (daytime max. $27^{\circ} \mathrm{C}$; night time min. $14^{\circ} \mathrm{C}$ );

(2) in a domestic refrigerator $\left(\max .9^{\circ} \mathrm{C}\right.$; min. $\left.2^{\circ} \mathrm{C}\right)$

(3) $0.16 \mathrm{~g}$ of powdered boric acid (Analar grade; BDH Chemicals Ltd, Poole, England) was dissolved in $9 \mathrm{ml}$ of each specimen to give a $1.8 \%$ solution of boric acid in urine. This series was held at room temperature (max. $28^{\circ} \mathrm{C}$; $\min .10^{\circ} \mathrm{C}$ );

(4) A $30 \% \mathrm{NaCl}-3 \%$ PVP solution was prepared by dissolving $30 \mathrm{~g}$ of $\mathrm{NaCl}$ (Analar grade; $\mathrm{BDH}$ ) and $3 \mathrm{~g}$ of powdered PVP (mol. wt approx. $44000 ; \mathrm{BDH})$ in $100 \mathrm{ml}$ distilled water. The solution was autoclaved and the resulting two layers were recombined by shaking. Three millilitres of this solution was added to $7 \mathrm{ml}$ of each specimen and held at room temperature $\left(\max .28^{\circ} \mathrm{C}\right.$; $\min .18^{\circ} \mathrm{C}$ );

(5) A NaCl-PVP solution containing PVP of mol. wt approx. $700000(\mathrm{BDH})$ was prepared as in
(4) above; $3 \mathrm{ml}$ was added to $7 \mathrm{ml}$ of each specimen and held at room temperature $\left(\max .27^{\circ} \mathrm{C}\right.$; $\left.\min .18^{\circ} \mathrm{C}\right)$.

The viable count of each simulated specimen was determined by both methods on at least three occasions between 4 and 78 hours.

\section{SENSITIVITY AND SPECIFICITY OF THE}

FILTER-PAPER-STRIP TEST

The sensitivity is the number of specimens that gave a result of $>10^{5} \mathrm{cfu} / \mathrm{ml}$ by both methods as a percentage of the number that gave that result by the surface viable count. The specificity is the number of specimens that gave a result of $<10^{5}$ $\mathrm{cfu} / \mathrm{ml}$ by both methods as a percentage of the number that gave that result by the surface viable count.

\section{Results}

The following results were obtained with six test strains in simulated specimens held under five different conditions; there were six graded specimens for each strain in each of the five series, ie, 36 specimens were held under each set of conditions.

\section{UNPRESERVED SPECIMENS AT ROOM} TEMPERATURE

Each test strain multiplied rapidly and the surface viable counts showed concentrations of between $10^{7}$ and $10^{8} \mathrm{cfu} / \mathrm{ml}$ within 72 hours in every simulated specimen. Of 21 specimens that gave results of $<10^{4} \mathrm{cfu} / \mathrm{ml}$ at time zero, 15 gave results of $>10^{5}$ $\mathrm{cfu} / \mathrm{ml}$ and two of $>10^{4}$ but $<10^{5} \mathrm{cfu} / \mathrm{ml}$ after 24 hours. The results obtained with the strain of $E$. coli are shown in Fig. 1a.

In the filter-paper-strip test, 22 specimens gave results of $<10^{4} \mathrm{cfu} / \mathrm{ml}$ at time zero but only four gave this result after 24 hours; two of these were infected with Ps. aeruginosa and two with $\boldsymbol{P r}$. mirabilis. After 72 hours, all the specimens gave results of $>10^{5} \mathrm{cfu} / \mathrm{ml}$ except one specimen in the $P s$. aeruginosa series that gave a result of $>10^{4}$ but $<10^{5} \mathrm{cfu} / \mathrm{ml}$. The test had a sensitivity of $85 \%$ and a specificity of $98 \%$ for unpreserved specimens.

\section{REFRIGERATED SPECIMENS}

The surface viable counts for all the simulated specimens remained constant for 72 hours; the results obtained with the strain of $E$. coli are shown in Fig. 1b.

In the filter-paper-strip test the number of results in the range $<10^{4} \mathrm{cfu} / \mathrm{ml},>10^{4}$ but $<10^{5} \mathrm{cfu} / \mathrm{ml}$, and $>10^{5} \mathrm{cfu} / \mathrm{ml}$ generally remained the same throughout. However, two specimens that gave results of $>10^{4}$ but $<10^{5} \mathrm{cfu} / \mathrm{ml}$ of the test strain of $E$. coli 

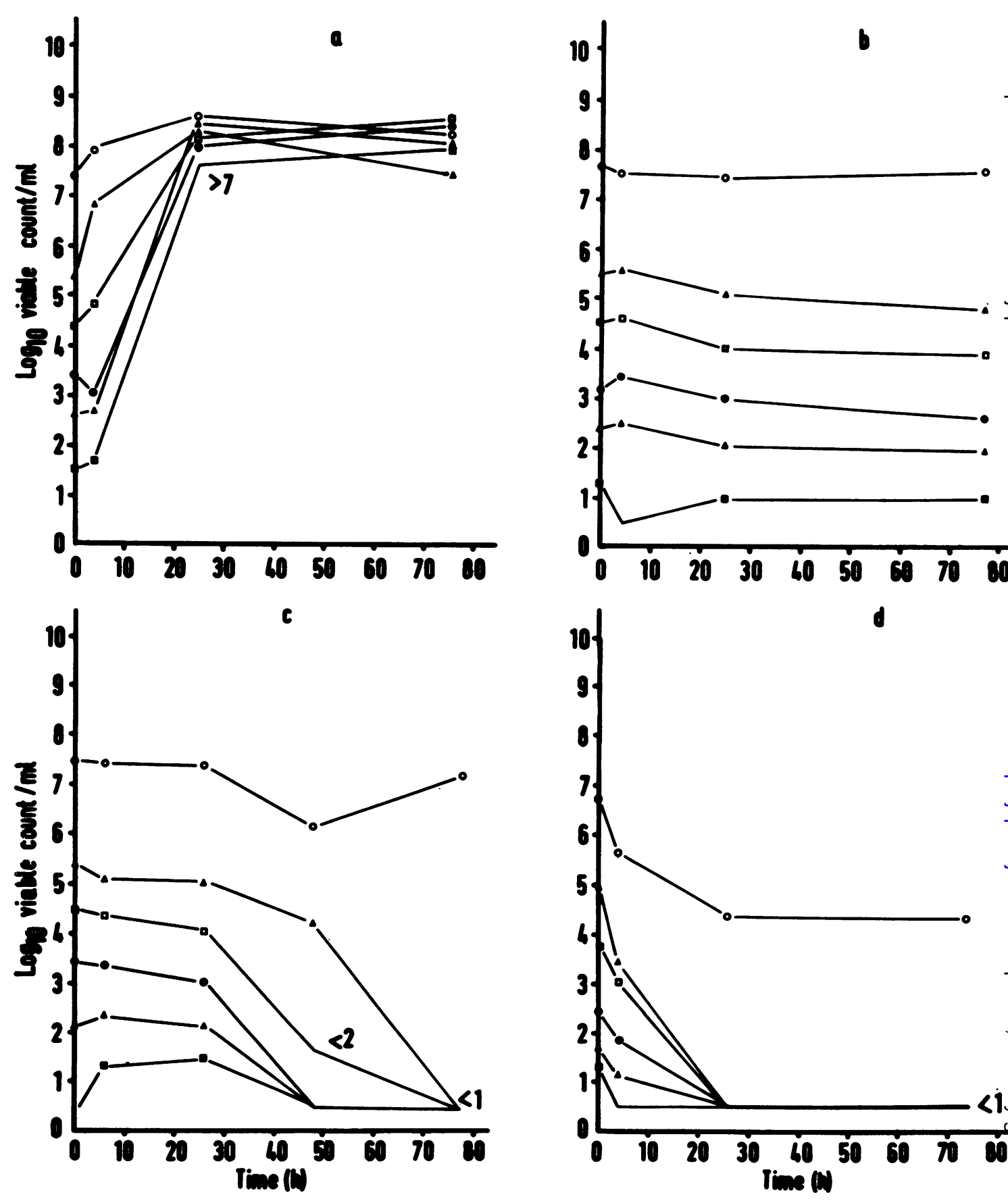

Fig. 1 Surface viable counts of the test strain of E. coli in simulated specimens of urine held for 72 hours:

(a) unpreserved specimen at room temperature; (b) refrigerated specimen; (c) specimens with $1 \cdot 8 \%$ boric acid;

(d) specimens with $9 \% \mathrm{NaCl}-0.9 \% \mathrm{PVP}$ 
at time zero gave results of $<10^{4} \mathrm{cfu} / \mathrm{ml}$ after 24 hours. The test had a sensitivity of $62 \%$ and a specificity of $100 \%$ for refrigerated specimens.

SPECIMENS WITH $1.8 \%$ BORIC ACID

The surface viable counts of five test strains remained constant for 24 hours, but the viable counts of all the specimens that were infected with $P$ s. aeruginosa fell markedly. After 24 hours the viable counts of all the specimens in the $E$. coli series, except for the most heavily infected specimen, declined (Fig. 1c). The viable counts of the specimens in the $K$. aerogenes, Micrococcus, Pr. mirabilis, and Strep. faecalis series and the specimen that was most heavily infected with $E$. coli remained constant for 72 hours.

In the filter-paper-strip tests with all six strains the number of specimens that gave results of $>10^{5} \mathrm{cfu} / \mathrm{ml}$ did not change, but many specimens that gave results of $>10^{4}$ but $<10^{5} \mathrm{cfu} / \mathrm{ml}$ at time zero gave results of $<10^{4} \mathrm{cfu} / \mathrm{ml}$ after 72 hours. The test had a sensitivity of $80 \%$ and a specificity of $100 \%$ for specimens with boric acid.

SPECIMENS WITH $9 \% \mathrm{NaCl}-0.9 \%$ PVP

There was no difference between the results obtained with PVP of the two molecular weights. The surface viable counts of all the specimens in the $E$. coli series fell markedly within 24 hours, except the viable count of the most heavily infected specimen which fell more slowly (Fig. 1d). In the $K$. aerogenes series the viable count of the most heavily infected specimen remained constant but the viable counts of the other specimens fell slowly. The test strain of Micrococcus grew in the simulated specimens preserved in this way. However, after 24 hours the viable counts remained in the same range that they were in at time zero except for one specimen that gave a result of $<10^{4} \mathrm{cfu} / \mathrm{ml}$ at time zero and $>10^{4}$ but $<10^{5} \mathrm{cfu} / \mathrm{ml}$ after 24 hours. The viable counts of specimens in the Strep. faecalis series remained constant for 72 hours but the viable counts of all specimens in the Pr. mirabilis and Ps. aeruginosa series fell markedly within 24 hours.

In the filter-paper-strip tests with the Gramnegative strains, many specimens that gave results of $>10^{5} \mathrm{cfu} / \mathrm{ml}$ at time zero gave results of $<10^{4}$ cfu/ml after 24 hours. In tests with the Micrococcus series, many specimens that gave results of $<10^{4}$ $\mathrm{cfu} / \mathrm{ml}$ at time zero gave results of $>10^{5} \mathrm{cfu} / \mathrm{ml}$ or $>10^{4}$ but $<10^{5} \mathrm{cfu} / \mathrm{ml}$ after 72 hours. The test had a sensitivity of $40 \%$ and a specificity of $100 \%$ for specimens with $\mathrm{NaCl}-\mathrm{PVP}$ (mol. wt 44000 ); the sensitivity was $81 \%$ and the specificity was $100 \%$ for specimens with $\mathrm{NaCl}-\mathrm{PVP}$ (mol. wt 700 000).

\section{Discussion}

The six test strains were chosen because $E$. coli, $3^{*}$
Micrococcus subgroup 3, $\mathrm{Pr}$, mirabilis, $K$. aerogenes, and Strep. faecalis are the most common species that cause primary urinary tract infection (Gould, 1968; Kerr, 1973) and Ps. aeruginosa is a potential pathogen in the urinary tract that can grow in conditions that are unfavourable to many species. Urine from male donors was used because uncontaminated urine can be collected more easily from males than from females.

The results confirm that organisms multiply rapidly from small inocula to high concentrations in urine at room temperature. When delay is inevitable, Kass (1956) recommended that a refrigerated specimen of urine should be cultured within 48 hours. In the present series of tests, refrigeration preserved the viable counts of all simulated specimens for at least 72 hours.

$E$. coli is the most common cause of primary urinary tract infection (Gould, 1968) and any preservative must be effective for specimens infected with this species. In the present study $1.8 \%$ boric acid was toxic for the test strain of $E$. coli. The viable counts of specimens that contained moderate but significant numbers of $E$. coli were maintained for 24 hours but then declined, although the viable count of the most heavily infected specimen was maintained for 72 hours. The viable counts of specimens that contained Pr. mirabilis also fell, and this species is also an important cause of primary urinary tract infection (Gould, 1968). These results differ from the results of Porter and Brodie (1969), who found a decrease in the viable counts of clinical specimens infected with Proteus or Klebsiella species but did not report any decline of $E$. coli after three days. The preservation of the viable count of the most heavily infected specimen in the $E$. coli series (between $10^{7}$ and $10^{8} \mathrm{cfu} / \mathrm{ml}$ at time zero) indicates that there may be a protective effect related to inoculum size, but when the experiment was repeated the viable count of a specimen containing between $10^{6}$ and $10^{7} \mathrm{cfu} / \mathrm{ml}$ at time zero fell after 24 hours. However, the viable counts of specimens from many cases of urinary tract infection are $>10^{8}$ organisms/ $\mathrm{ml}$ (Norden and Kass, 1968) and if either a protective inoculum effect or a slow decline occurred, the viable count would remain significant after three days. Similarly, it is unimportant if a specimen that contained $10^{3}$ or $10^{4} \mathrm{cfu} / \mathrm{ml}$ at time zero is sterile after three days. It could be argued, therefore, that boric acid may significantly alter the results obtained only with specimens that contain between $10^{4}$ and $10^{7} \mathrm{cfu} / \mathrm{ml}$ at time zero.

The NaCl-PVP solutions were not successful preservatives. There was a rapid decline in the viable counts of specimens containing $E$. coli, although there was again some evidence for a protective 
inoculum effect. The growth of Micrococcus subgroup 3 in specimens treated in this way reflects the salt-tolerance of this species (Baird-Parker, 1965). Amies and Corpas (1971) did not report any reduction in numbers of their test strains or the growth of a salt-tolerant strain of Staphylococcus albus.

Any preservative in routine use must be compatible with the method used to determine the viable count. A surface viable count is too time-consuming and expensive for routine use, and most laboratories use a semiquantitative method of culture. The specificity of the filter-paper-strip method (Ryan et al., 1962) in these tests was high but the sensitivity was generally low, probably because few of the simulated specimens were heavily infected and the proportion of specimens that contained approximately $10^{5}$ $\mathrm{cfu} / \mathrm{ml}$ was much larger than in clinical practice. The sensitivity of the test was much lower for refrigerated specimens and specimens treated with $\mathrm{NaCl}-\mathrm{PVP}$ (mol. wt 44000 ) but was unaffected by boric acid or NaCl-PVP (mol. wt 700 000). These results indicate that the method of preservation and even the molecular weight of very similar preservatives may affect the compatibility of the methods of preservation and semiquantitative culture. Further work must be done to clarify this problem.

The results of this study confirm the need for a method of preserving urine specimens when they cannot be examined immediately. Refrigeration is effective and reliable; the addition of boric acid may be satisfactory for most clinical specimens, but the $\mathrm{NaCl}-\mathrm{PVP}$ solution is not suitable. It is important to ensure the compatibility of the method of detecting significant bacteriuria with the method of preservation, and to perform the appropriate calibration experiments.

We should like to thank Professor B. P. Marmion and Professor J. G. Collee for encouragement and advice. The studies were undertaken as part of a
BSc (Hons; medical science) research project by $\underline{\underline{\sigma}}$ PGW.

\section{References}

Amies, C. R. and Corpas, A. (1971). A preservative for $\frac{\overline{\bar{c}}}{\sqrt{3}}$ urine specimens in transit to the bacteriological $\overparen{D}$ laboratory. J. med. Microbiol., 4, 362-365.

Asscher, A. W., Sussman, M., and Weiser, R. (1968). Bacterial growth in human urine. In Urinary Tract $\vec{O}$ Infection, edited by F. O'Grady and W. Brumfitt, pp. 3-13. Oxford University Press, London.

Baird-Parker, A. C. (1965). The classification of staphylococci and micrococci from world-wide sources. J. gen.용 Microbiol., 38, 363-387.

Cowan, S. T. and Steel, K. J. (1965). Manual for the Identification of Bacteria. Cambridge University Press, of London.

Cruickshank, R. (1968). Medical Microbiology, p. 794. 11 th edition, revised. Livingstone, Edinburgh.

Duerden, B. I. and Moyes, A. (1976). Comparison of laboratory methods in the diagnosis of urinary tract infection. J. clin. Path., 29, 286-291.

Gould, J. C. (1968). The comparative bacteriology of $\vec{\varphi}$ acute and chronic urinary tract infection. In Urinary Tract Infection, edited by F. O'Grady and W. Brumfitt, pp. 43-48. Oxford University Press, London.

Kass, E. H. (1956). Asymptomatic infections of the urinary tract. Trans. Ass. Amer. Phycns, 69, 56-64.

Kass, E. H. (1957). Bacteriuria and the diagnosis of infections of the urinary tract. Arch. intern. Med., $100 \stackrel{\square}{\circ}$ 709-714.

Kerr, H. (1973). Urinary infection caused by Micrococcus subgroup 3. J. clin. Path., 26, 981-920.

Miles, A. A., Misra, S. S., and Irwin, J. O. (1938). The estimation of the bactericidal power of the blood. J. Hyg. (Lond.), 38, 732-749.

Norden, C. W. and Kass, E. H. (1968). Bacteriuria of pregnancy-a critical appraisal. Ann. Rev. Med., 19, 431-470.

Porter, I. A. and Brodie, J. (1969). Boric acid preservation of urine samples. Brit. med. J., 2, 353-355.

Ryan, W. L., Hoody, S., and Luby, R. (1962). A simple $ᄋ$ quantitative test for bacteriuria. J. Urol., 88, 838-840. 